\title{
A relação dialética entre arte e sociedade em Theodor W. Adorno*
}

\author{
The Dialectical Relationship between art and Society \\ in Theodor W. Adorno
}

${ }^{* *}$ Franciele Bete Petry

\begin{abstract}
Resumo: O trabalho pretende discutir o duplo caráter das obras de arte a partir da obra de Theodor W. Adorno. Pretende-se examinar os argumentos sustentados pelo autor sobre o caráter social das obras, principalmente, no caso da música, em que se pode perceber como o desenvolvimento do próprio material musical expressa as aporias encontradas na sociedade. Por meio de uma crítica dialética, Adorno discute tanto o modo pelo qual as obras de arte respondem às contradições da sociedade, colocando-se, assim, como força de resistência à reificação, quanto a influência negativa que sofrem, por exemplo, no contexto da indústria cultural. Além disso, o artigo pretende se dedicar à reflexão sobre a autonomia das obras de arte, qualidade que as mantém fechadas, desenvolvendo-se apenas segundo leis formais internas, sem que atendam a uma função social. É nesse sentido que se coloca a exigência de uma determinada forma de recepção das obras, orientada não pela fruição, mas pela possibilidade de interpretar seu teor de verdade. Assim, a dialética presente no modo como as obras se relacionam com a sociedade torna possível concebê-las como possibilidade de crítica à realidade e de resistência à reificação.
\end{abstract}

Palavras-chave: Adorno. Arte. Sociedade. Reificação.

Abstract: The work aims at discussing the double character of works of art in Adorno's writings. It will be examined the arguments defended by Adorno about the social character of art, especially in the case of music, in which can be seen how the development of the material expresses the contradictions of society. By means of a dialectical critique Adorno discuss the way in which works of art respond to the social problems

* O artigo apresenta uma parte da Tese de Doutorado da autora (2011), intitulada Além de uma crítica à razão instrumental.

* * Doutora em Filosofia e em Educação pela Universidade Federal de Santa Catarina. Professora do Departamento de Estudos Especializados em Educação da Universidade Federal de Santa Catarina.<ffpetry@yahoo.com.br>. 
and become possibilities of resistance to reification. It will be also analyzed the negative influence of culture industry on works of art. Therefore, the paper reflects about the concept of autonomous art as the hermetic character of works of art that enable them a development according their internal rules, without being submitted to a social function. In this sense, it is necessary that the reception of works of art be determined not by the aesthetic pleasure, but by the possibility of disclosing their truth content. The dialectic relation between art and society makes works of art critical and resistant to reification.

Keywords: Adorno. Art. Society. Reification.

\section{0 caráter social da arte}

A tensão existente entre a autonomia da arte e sua relação com a 1 sociedade ocupa lugar central nos escritos de Adorno. Mais do que uma tensão, ela se expressa nos termos de uma contradição. $\mathrm{Na}$ Teoria Estética, Adorno afirma que "a liberdade absoluta na arte, que é sempre a liberdade num domínio particular, entra em contradição com o estado perene de não-liberdade no todo. O lugar da arte tornou-se nele incerto" (ADORNO, 2008b, p. 11). Com a modernidade, a arte se emancipa de sua função social associada à religião e à política e passa a se desenvolver em uma dimensão de liberdade que lhe permite uma nova forma de se constituir. Desvinculada dos rituais e do culto que estavam presentes em sua origem, Adorno defende que a arte passou a se relacionar com o conceito de humanidade, o qual, porém, em uma sociedade cada vez menos humana, acaba por colocar em risco a própria possibilidade de que a arte se constitua de forma autônoma. De acordo com ele, "a sua autonomia começa a ostentar um momento de cegueira, desde sempre peculiar à arte. Na época de sua emancipação, este momento eclipsa todos os outros, apesar ou se é que não por causa da não-ingenuidade a que já, segundo Hegel, não mais se pode esquivar" (ADORNO, 2008b, p. 12). Compreender o problema da autonomia da arte em uma sociedade reificada e marcada pelo predomínio de uma racionalidade instrumental exigirá, então, concebê-la em seu movimento histórico e dialético, o qual estará intimamente conectado à forma com que as mais variadas manifestações estéticas se apresentam.

A concepção relativa ao caráter social da arte tal como Adorno a desenvolve em Teoria estética aparece em outros escritos seus muitos anos antes. Já na década de 1930, a relação entre a arte e a sociedade se colocava como objeto de crítica do autor. No texto Sobre a situação social da música (Zur gesellschaftlichen Lage der Musik) de 1932, Adorno discute o modo pelo qual a música conseguiria expressar as contradições sociais 
por meio do desenvolvimento imanente de suas formas, assim como pelo domínio do material e das soluções que oferece a seus problemas. ${ }^{1}$ Nesse sentido, a arte surge como esfera capaz de se opor à sociedade, ainda que dela não se desvincule, uma vez que ambas estão em uma relação de tensão. As antinomias sociais são expressas não de forma direta ou imediata, mas como linguagem formal presente na música. De acordo com Adorno,

a questão é, ainda, em que medida a música, enquanto ela mesmo deve intervir no processo social, está em posição de intervir como arte. Em todo caso, hoje e aqui a música é capaz de nada mais além de representar, em sua própria estrutura, as antinomias sociais que também portam a culpa de seu isolamento. A música será tanto melhor, quanto mais profundamente ela for capaz de expressar, em sua forma, o poder daquelas contradições e da necessidade de sua superação social; quanto mais puramente ela pronunciar, nas antinomias de seu próprio idioma de forma, a ânsia da condição social, e clamar pela mudança na escrita cifrada do sofrimento. Não lhe serve olhar para a sociedade numa consternação perdida: ela realiza sua função social de maneira mais precisa quando, em seu próprio material e de acordo com suas próprias leis da forma, apresenta os problemas sociais contidos nas células mais profundas de suas técnicas. A tarefa da música como arte assume, assim, uma certa analogia face à teoria social (ADORNO, 2003, p. 731, tradução nossa).

A função social que a música adquire, porém, não está relacionada a um "uso" que dela possa ser feito, mas à capacidade que possui de revelar em sua mediação formal um conteúdo [Gehalt] que é histórico e social. Por meio da composição, da disposição das técnicas e do material artístico, seria possível realizar uma determinada leitura da realidade. $\mathrm{O}$ conceito de material, como afirma Almeida, escapa a uma mera definição, "não apenas por fazer parte de uma constelação de conceitos, na qual o sentido de cada um depende dos demais, mas principalmente por assumir, em seu próprio sentido, a historicidade que aponta em seu objeto" (ALMEIDA, 2007, p. 288). É por isso que a crítica feita por Adorno parte não exatamente de tal conceito, mas do modo como ele surge a partir de um entrelaçamento dialético entre a obra de arte, o artista e a sociedade. Na medida em que o material musical contém tais relações, ele se torna capaz de estabelecer posições de afirmação ou negação da sociedade.

\footnotetext{
${ }^{1}$ Para um estudo aprofundado da estética adorniana, com ênfase nos escritos sobre música, recomenda-se uma consulta ao trabalho de Paddison, intitulado Adorno's aesthetics of music de 1993 e ao trabalho de Almeida, Crítica dialética em Theodor W. Adorno: música e verdade nos vinte, de 2007 .
} 
A música, tal como a teoria, pode expressar as aporias encontradas na sociedade e, mais do que isso, transformá-las em conteúdos aos quais se pode atribuir o caráter de "cognitivos". Esses conteúdos, no entanto, estão presentes na relação da música com o material musical. Como afirma Paddison, "é tarefa de tal música dar uma forma clara e precisa aos problemas oferecidos pelo material. [...] As soluções que a música oferece aos problemas suscitados pelo material tem, em termos musicais, o estatuto e o caráter cognitivo das teorias sociais" (PADDISON, 1993, p. 100, tradução nossa). Não se trata, assim, de mostrar a realidade e suas contradições como se a arte ou a teoria fossem retratos do objeto que refletem, mas de apresentá-los em sua estrutura imanente, tanto como domínio do material artístico que permitirá a expressão de um teor de verdade, quanto na forma do pensamento abordar seu objeto em sua não-identidade. De acordo com Adorno,

assim, a relação da música e da sociedade contemporâneas é igualmente problemática em todas as direções. Ela partilha suas aporias com a teoria social; ao mesmo tempo, porém, também os modos de comportamento, através dos quais esta deveria se contrapor ou enfrentar as aporias. $\mathrm{Da}$ música que, hoje, quer provar o seu direito de viver, deve-se - de certo modo - exigir um caráter cognitivo. No seu material ela precisa modelar claramente aqueles problemas que o material lhe coloca - material este que nunca é puramente natural, mas material sócio-historicamente produzido; as soluções, que ela encontra nesse andar, igualam-se a teorias [...] (ADORNO, 2003, p. 731, tradução nossa).

Além disso, Adorno procura mostrar que do mesmo modo que a teoria está em uma relação dialética com a práxis, também a música assumiria tal posição. A Teoria Crítica, desde o ensaio de Horkheimer da década de 1930, Teoria tradicional e teoria crítica, comprometeu-se com a superação da falsa consciência por meio de uma nova forma de promover a relação entre sujeito e objeto. O método dialético presente na elaboração conceitual orientou a atividade crítica com a finalidade de trazer à expressão as contradições que foram banidas do pensamento filosófico tradicional e, assim, colocou em prática uma atitude constantemente voltada para o enfrentamento das questões relacionadas à dominação e ao surgimento de novas formas de reificação social, as quais não apenas bloqueiam a superação dessa falsa consciência como criam instâncias nas quais ela é fortalecida, como é o caso, por exemplo, da esfera cultural.

A música, especificamente, não está excluída dessas relações. Por um lado, sofre as consequências da intensificação dos processos de reificação, mas, por outro, é capaz de se manter autônoma e, precisamente 
por isso expressar a alienação de forma negativa, já que dela conseguiu se separar. Contudo, tal superação não ocorre simplesmente por uma referência direta às antinomias, mas pela sua incorporação na estrutura artística. Da mesma forma que a crítica ao esclarecimento não se constituiu, por si só, na superação do pensamento identificante, pois seria preciso ir além do reconhecimento da própria vinculação com a dominação e formular uma nova maneira de pensar a relação entre os conceitos e seus objetos, também a música poderia superar a falsa consciência pela rejeição de determinadas formas estéticas e pelo estabelecimento de possibilidades distintas de construção imanente, principalmente porque o material de que dispõe não é algo natural, mas objetivação social e histórica. Como afirma Adorno,

assim como a teoria vai além da consciência presente das massas, também a música precisa ir além. Porém, assim como a teoria se coloca numa relação dialética com a prática, à qual ela não apenas põe demandas, mas da qual também incorpora demandas, também uma música que tenha alcançado a autoconsciência de sua função social assumirá uma relação dialética com a prática. Isso não acontecerá caso hoje e aqui, na condição de mercadoria, na aparência da imediaticidade, submeta-se ao 'uso'; antes em que, em consonância com o estatuto da teoria social, forme todos aqueles elementos, cuja intenção objetiva é a superação da dominação de classes, bem como cujo desenvolvimento ocorra, durante a dominação de classes, de modo socialmente isolado e celular (ADORNO, 2003, p. 732, tradução nossa).

Adorno defende que a relação dialética entre a música e a práxis ocorre na medida em que a primeira não se reduz a uma simples mercadoria. Ainda que dependa do material musical produzido pela sociedade, ela se torna crítica ao negá-lo em sua estrutura formal. De acordo com Paddison, "Adorno considera que a função crítica da música radical repousa na sua negação das categorias musicais em face da sua assimilação e afirmação histórica pela indústria cultural" (PADDISON, 1993, p. 101, tradução nossa). Assim, a música incorpora e ao mesmo tempo nega as categorias que a constituem. Em sua atitude negativa frente ao material musical, ela oferece resistência à sociedade. Adorno observa que é possível "invalidar as categorias burguesas fundamentais, tais como a personalidade criativa e a expressão da alma dessa personalidade, o mundo dos sentimentos privados e a interioridade transfigurada, colocando, em seu lugar, princípios de construção altamente racionais e transparentes" (ADORNO, 2003, p. 733, tradução nossa), de tal forma que a música, devido a seu movimento dialético em relação ao material, possa ser crítica da sociedade na qual emerge e, portanto, portadora de uma dimensão cognitiva. 
A questão do desenvolvimento do material musical, como destaca Almeida, tem um elemento paradoxal, também comentado por Paddison, pois se a ênfase de Adorno está no material e não nas obras individuais, são estas, contudo, que possibilitam o acesso a ele. Assim, diz Almeida, "a contradição aparentemente expressa na teoria é na verdade a percepção de uma contradição real, sendo portanto inteiramente justificada" (ALMEIDA, 2007, p. 299). É porque o material consiste no critério para se avaliar a consistência e verdade das obras musicais que ele só pode ser examinado a partir delas. Nesse sentido, por exemplo, é que a crítica de Adorno reconhece no dodecafonismo uma técnica capaz de expressar, como diz Almeida, "as contradições expressionistas entre o Eu e as formas, a natureza e a racionalidade, a construção e a expressão, a necessidade e a liberdade" (ALMEIDA, 2007, p. 247). Schönberg adquire uma importância central na crítica de Adorno por ter sido alguém capaz de desenvolver a dialética do material musical:

quando o Schoenberg esotérico não estiver reservado a uma história da música como história do espírito, ou seja, especializada e socialmente irrelevante, mas for, antes, uma figura a ser projetada sobre a dialética social a partir da perspectiva de sua dialética material, então isso se justifica pelo fato de ele ter encontrado, na forma dos problemas materiais, que ele adotou e aos quais deu continuidade, os problemas da sociedade que produziam esse material e, nele, dispunham as contradições como problemas técnicos (ADORNO, 2003, p. 738, tradução nossa).

Schönberg teria clarificado e racionalizado as categorias da música burguesa e combinado a essa mudança uma alteração na função expressiva ao se libertar do sistema tonal. Como explica Safatle, "a 'emancipação da dissonância' em relação ao esquema antecipação-resolução, emancipação a respeito da qual fala constantemente Schoenberg não seria outra coisa que a possibilidade de construir idéias musicais capazes de desvelar uma expressão recalcada pela gramática do sistema tonal" (SAFATLE, 2007, p. 84). Daí a importância que o compositor atribuía a Freud e a originalidade com que buscou respostas ao problema objetivo de encontrar uma mediação entre o material musical e os impulsos que sob o sistema tonal se encontravam bloqueados. O problema consistiria, então, em encontrar um modo pelo qual o material, que por sua vez é herdado de uma tradição, pudesse ser submetido à expressão radical da psique. Para Adorno, Schönberg só alcança uma resposta a ele porque

abandona todas as ligações prévias, os reflexos de uma 'concordância' da sociedade burguesa com a psiquê do indivíduo, que agora está anunciada por seu sofrimento - que se encontram no caminho da liberalidade da 
expressão individual. São essas as relações de simetria musicais que, sob todo ponto de vista, encontram-se ultrapassadas, baseadas sobre uma técnica da repetição, e sua crítica ocorre, novamente em consonância com Karl Kraus, mas também com as intenções arquitetônicas de Adolf Loos, como crítica de todo ornamento. Com a limitação de todos os elementos musicais essa crítica não permanece na arquitetura musical, cuja simetria e cujo ornamento ela nega; ela vai igualmente rumo ao correlato harmônico da relação tectônica de simetria, a tonalidade que é, ao mesmo tempo, atingida pela dissonância como portador do princípio de expressão radical; com o desmonte do esquema de tons o contraponto até então acuado se emancipa e produz aquela forma de polifonia que é conhecida pelo nome de ‘linearidadeı; finalmente, também se ataca o som total, homogêneo, como é portado pela substância do conjunto dos instrumentos de corda [Streichertutti] da orquestra (ADORNO, 2003, p. 737, tradução nossa).

Dessa forma, em Schönberg se encontra um princípio de construção que, vinculado a um caráter expressivo, desenvolveu-se formalmente como tentativa de dar uma resposta a um problema objetivo. Tal é o potencial dialético que Adorno reconhece no compositor, o qual conseguiu expressar a alienação social por meio da superação das categorias burguesas do estilo.

A atenção dada por Adorno à relação entre a música e a sociedade também é central em seu texto $O$ fetichismo na música e a regressão da audição de 1938. Nele, Adorno discute a função social da música, cada vez mais absorvida pelos mecanismos da indústria cultural. De forma correspondente, há no plano subjetivo uma regressão: "a liquidação do indivíduo constitui o sinal característico da nova época musical em que vivemos" (ADORNO, 1975, p. 178). Adorno apresenta uma série de críticas ao modo como a música se submete ao mercado, as quais aparecem posteriormente em outros escritos, como o capítulo da Dialética do esclarecimento dedicada ao tema da indústria cultural. A produção musical, ao ser determinada pelo mercado, é modificada em sua própria estrutura. O sucesso passa a depender do dinheiro gasto pelo consumidor para apreciar uma obra ou comprá-la, fazendo com que o indivíduo se coloque em uma situação de alienação, na medida em que ele "fabrica" o sucesso, "que ele coisifica e aceita como critério objetivo, porém sem se reconhecer nele" (ADORNO, 1975, p. 181). O valor de troca se transforma em qualidade dos bens culturais, conferindo-lhes a aparência de imediatidade que os reduz a simples mercadorias. Para Adorno,

é nesse qüiproquó específico que consiste o específico caráter fetichista da música: os efeitos que se dirigem para o valor de troca criam a aparência do imediato, e a falta de relação com o objeto ao mesmo tempo desmente tal aparência. Esta carência de relação baseia-se no caráter 
abstrato do valor de troca. De tal processo de substituição social depende toda a satisfação substitutiva, toda a posterior substituição 'psicológica' (ADORNO, 1975, p. 181).

A essa alteração na função da música, que passa a ser objeto de consumo e entretenimento, corresponde uma modificação também no modo como a arte se relaciona com a sociedade. A crítica de Adorno se remete à presença do valor de troca como determinante tanto na produção dos bens culturais, quanto na recepção, já que os indivíduos reduzem sua relação com a arte ao consumo, excluindo-a da possibilidade de ser um meio para uma experiência estética. Assim, diz Adorno, "diante dos caprichos teológicos das mercadorias, os consumidores se transformam em escravos dóceis; os que em setor algum se sujeitam a outros, neste setor conseguem abdicar de sua vontade, deixando-se enganar totalmente" (ADORNO, 1975, p. 182). Além disso, o processo de mercadorização modifica a estrutura das obras, impedindo que elas possuam um momento de negação da realidade. Nelas, a tensão é um elemento ausente e, sem esse momento, as obras se tornam apenas extensão do mercado na esfera cultural, incapazes de opor resistência à reificação da qual, ao mesmo tempo, são produtos. Segundo Adorno, "o processo de coisificação atinge a sua própria estrutura. Tais obras transformam-se em um conglomerado de idéias, de 'achados', que são inculcadas aos ouvintes através de amplificações e repetições contínuas, sem que a organização do conjunto possa exercer a mínima influência contrária" (ADORNO, 1975, p. 183).

Adorno observa, assim, dois fenômenos: um processo de coisificação que atinge as obras e as reduz a mercadorias culturais, sem qualquer capacidade de oposição à realidade, envoltas, portanto, em um fetichismo e, por outro lado, uma situação de regressão da audição, a qual não se refere a um retrocesso individual nem coletivo no desenvolvimento musical dos ouvintes, mas a um estado infantil da audição moderna. Para Adorno,

os ouvintes perdem com a liberdade de escolha e com a responsabilidade não somente a capacidade para um conhecimento consciente da música que sempre constitui prerrogativa de pequenos grupos - mas negam com pertinácia a própria possibilidade de se chegar a um tal conhecimento. Flutuam entre o amplo esquecimento e o repentino reconhecimento, que logo desaparece de novo no esquecimento. [...] A repressão efetua-se em relação a esta possibilidade presente; mais concretamente, constatase uma regressão quanto à possibilidade de uma outra música, oposta a essa. Regressivo é, contudo, também o papel que desempenha a atual música de massas na psicologia das suas vítimas (ADORNO, 1975, p. 188). 
O processo de reificação que atinge a esfera cultural tem como consequência não apenas a redução da escolha entre produtos que não se diferenciam, mas, principalmente, a modificação da relação entre o indivíduo e a arte, a qual possui um caráter dialético, pois, por um lado, o sujeito dificilmente se depara com obras de arte "autênticas", incapaz, assim, de realizar uma experiência estética. Por outro lado, o modo como os produtos culturais são oferecidos gera no indivíduo uma determinada forma de recepção, a qual impede, igualmente, aquela experiência estética que ele poderia realizar com a arte. Para Adorno, "o modo do comportamento perceptivo, através do qual se prepara o esquecer e o rápido recordar da música de massas, é a desconcentração" (ADORNO, 1975, p. 190). Benjamin, em seu texto A obra de arte na era de sua reprodutibilidade técnica já havia chamado a atenção para o modo como a recepção das obras pelas massas se alterou na modernidade, sendo a distração um modelo para as novas formas estéticas, principalmente para o cinema. De acordo com Benjamin,

através da distração, como ela nos é oferecida pela arte, podemos avaliar, indiretamente, até que ponto nossa percepção está apta a responder a novas tarefas. E, como os indivíduos se sentem tentados a esquivar-se a tais tarefas, a arte conseguirá resolver as mais difíceis e importantes sempre que possa mobilizar as massas. É o que ela faz, hoje em dia, no cinema. A recepção através da distração, que se observa crescentemente em todos os domínios da arte e constitui o sintoma de transformações profundas nas estruturas perceptivas, tem no cinema o seu cenário privilegiado (BENJAMIN, 1994, p. 194).

Adorno chega inclusive a mencionar em seu texto a consideração acima referida de Benjamin. Contudo, critica tal forma de recepção, uma vez que a experiência estética exigiria do indivíduo atenção, envolvimento com a obra de arte e concentração. Como afirma Adorno, "se o filme como totalidade parece ser adequado para a apreensão desconcentrada, é certo que a audição desconcentrada torna impossível a apreensão de uma totalidade" (ADORNO, 1976, p. 190). A crítica que Adorno faz nesse texto está muito próxima daquela desenvolvida por ele em Teoria da semiformação de 1959, pois são justamente as qualidades de concentração e memória aquelas necessárias para um processo formativo capaz de criar no sujeito as forças de resistência aos processos de reificação, possibilitando a realização de experiências e a formação no sentido da autonomia. A crítica à fetichização da música pode então ser entendida como a denúncia de que o modo de produção da cultura para as massas não apenas altera a estrutura das obras de arte, mas impede que os indivíduos estabeleçam uma relação apropriada com a arte 
autêntica, algo que os conduziria a uma formação para a emancipação. Segundo Adorno,

a estrutura social e sua dinâmica impedem a esse neófitos os bens culturais que oferecem ao lhes negar o processo real da formação, que necessariamente requer condições para uma apropriação viva desses bens. Mas o fato de que os milhões que antes nada sabiam desses bens e que agora se encontram inundados por eles estejam muito precariamente preparados para isso, até mesmo do ponto de vista psicológico, talvez ainda não seja o mais grave. As condições da própria produção material dificilmente toleram o tipo de experiência sobre a qual assentavam os conteúdos formativos tradicionais que se transmitiam. Por isso, tudo o que estimula a formação acaba por lhe contrair os nervos vitais. Em muitos lugares já obstruiu, como pedantismo inócuo ou presunçosa insubordinação, o caminho do amanhã. Quem compreende o que é poesia dificilmente encontrará um posto bem pago como autor de textos publicitários. A diferença sempre crescente entre o poder e a impotência sociais nega aos impotentes - e tendencialmente também aos poderosos - os pressupostos reais para a autonomia que o conceito de formação cultural ideologicamente conserva (ADORNO, 2010, p. 16).

Nesse texto, Adorno defende a necessidade de se retomar o conceito de formação cultural (Bildung) como antídoto à reificação. Justifica-se, por isso, a insistência em noções como a de experiência, memória, concentração, as quais também sofreram influência dos escritos de Benjamin, tais como O narrador: considerações sobre a obra de Nikolai Leskov e Experiência e pobreza. No contexto da indústria cultural, a semiformação, enquanto negação da verdadeira formação cultural, torna-se uma noção correspondente, pois atende às exigências, no plano formativo, do processo de empobrecimento da subjetividade. Como diz Adorno, "o entendido e experimentado medianamente - semientendido e semiexperimentado - não constitui o grau elementar da formação, mas seu inimigo mortal. Elementos que penetram na consciência sem se fundir em sua continuidade se transformam em substâncias tóxicas" (ADORNO, 2010, p. 29). A ideia de que a subtração das condições necessárias à experiência estética e também formativa se constitui em um problema para a superação da própria situação de reificação e dominação já se encontrava de forma implícita no escrito O fetichismo da música e a regressão da audição, como, por exemplo, na seguinte passagem:

os ouvidos que somente têm capacidade para ouvir, naquilo que lhes é proporcionado, o que se lhes exige, e que registram o atrativo sensorial abstrato, ao invés de levarem os momentos de encantamento à síntese, constituem ouvidos de má qualidade: mesmo no fenômeno 'isolado', escaparlhes-ão traços decisivos, isto é, precisamente aqueles que permitem ao fenômeno transcender o seu próprio isolamento (ADORNO, 1975, p. 191). 
A partir dessas considerações, pode-se observar o papel social e formativo atribuído à arte, o que entra em tensão com sua autonomia. Para o conceito de formação cultural, tal como foi desenvolvido por Adorno em diferentes escritos, a experiência estética é um momento significativo por meio do qual o indivíduo entra em uma relação com o objeto de modo alternativo àquele do pensamento moldado segundo o princípio da identidade. Essa ideia pode ser entendida também em sua conexão com os argumentos que Adorno sustenta na Teoria estética, em que a experiência com a obra de arte autêntica é capaz de modificar a percepção que o indivíduo tem da realidade. Essa seria, incontestavelmente, uma qualidade essencial do processo formativo voltado para a emancipação dos sujeitos em uma sociedade marcada pela reificação.

\section{A autonomia da obra de arte}

Se, por um lado, Adorno reconhece o caráter social da arte tanto em uma forma positiva - uma vez que o material artístico pode ser a mediação entre um conteúdo histórico-social e o artista -, quanto negativa - pois a arte pode ser absorvida por interesses econômicos que alteram sua estrutura, conferindo-lhe uma função ideológica -, por outro, defende o conceito de autonomia da arte. Bürger, por exemplo, se refere a tal noção a partir da sua desvinculação da práxis social. Conforme a Teoria da vanguarda,

a autonomia da arte é uma categoria da sociedade burguesa. Ela permite descrever a ocorrência histórica do desligamento da arte do contexto da práxis vital, descrever o fato de que, portanto, uma sensibilidade não comprometida com a racionalidade-voltada-paraos-fins pode se desenvolver junto aos membros das classes que, pelo menos temporariamente, estavam livres da pressão da luta cotidiana pela sobrevivência. Aí reside o momento de verdade do discurso da obra de arte autônoma. No entanto, o que essa categoria não consegue abarcar é que esse desligamento da arte do contexto da práxis vital representa um processo histórico, vale dizer, socialmente condicionado (BÜRGER, 2008, p. 101).

Para o autor, é nesse isolamento da arte de seu pertencimento social que reside o caráter ideológico, o qual representa equivocadamente a possibilidade de se conceber a obra de arte como autônoma. Desse modo, o próprio conceito de autonomia se transforma em ideologia que esconde o caráter histórico e condicionado que compõe a obra de arte. A interpretação de Bürger, contudo, não permite compreender a duplicidade que tal conceito possui na obra de Adorno. Como também defende Harding, "quando Bürger argumenta que a autonomia da arte é uma categoria que descreve o descolamento da arte de contextos práticos,

Veritas | Porto Alegre, v. 59, n. 2, maio-ago. 2014, p. 388-406 
ele isola somente um aspecto (e assim prejudica) da dinâmica em jogo nas discussões de Adorno" (HARDING, 1992, p. 183, tradução nossa). Bürger desconsideraria que a separação da arte em relação à sociedade à qual Adorno se refere não torna a arte uma dimensão completamente alheia à vida ou a ela insignificante, ainda que sua relevância, como afirma Harding, "só possa ser colocada em termos negativos. Adorno usa a autonomia da arte para sustentar o valor de negatividade da arte, isto é, para sustentar a integridade das tensões negativas não-resolvidas (a não-identidade) que a obra tem em um momento histórico específico" (HARDING, 1992, p. 184, tradução nossa). ${ }^{2}$

Na Teoria Estética, Adorno procura mostrar como a arte, ao mesmo tempo em que se origina do mundo empírico, dele se separa no momento mesmo em que se constitui, negando sua própria origem. Assim, a arte se mostra superior à realidade quanto maior for a negatividade com que a apresenta. Como afirma Adorno, "as obras de arte destacam-se do mundo empírico e suscitam um outro com uma essência própria, oposto ao primeiro como se ele fosse igualmente uma realidade" (ADORNO, 2008b, p. 12). As obras de arte, portanto, são capazes de negar a realidade objetiva, mas não de forma integral, pois tal recusa em participar do mundo empírico se manifestará em sua forma. Quanto mais separada da sociedade, mais esta se fará presente na obra por meio de sua estrutura. A interpretação da forma estética, porém, deve ser feita com um olhar atento ao movimento que a constitui, que marca sua constituição formal, a qual é, ao mesmo tempo, representação de um conteúdo objetivo ligado, por sua vez, a um determinado tempo e sociedade. Essa forma de interpretação da obra de arte mantém, assim, uma vinculação ao método materialista dialético. De acordo com Adorno,

a arte só é interpretável pela lei do seu movimento, não por invariantes. Determina-se na relação com o que ela não é. O caráter artístico específico que nela existe deve deduzir-se, quando ao conteúdo, do seu Outro; apenas isto bastaria para qualquer exigência de uma estética materialista dialéctica. Ela especifica-se ao separar-se daquilo por que tomou forma; a sua lei de movimento constitui a sua própria lei formal. Ela unicamente existe na sua relação com o seu Outro e é o processo que a acompanha (ADORNO, 2008b, p. 14).

Desse modo, para Adorno a arte tem um momento afirmativo, ao mesmo tempo em que contém uma dimensão de negatividade. A

\footnotetext{
${ }^{2}$ Em geral, poder-se-ia afirmar que as obras de vanguarda fogem da visão adorniana de obra de arte, já que colocam em questão categorias tradicionais da estética (inclusive da adorniana), tais como as de autoria ou público, entre outras.
} 
afirmação nela presente se refere àquilo que projeta por meio de sua forma, ao passo que a negatividade se relaciona à recusa em participar do mundo empírico, ao qual ela se eleva no momento em que supera a ideia de uma finalidade e de uma função social, qualidades essas que não coincidem com seu caráter social. O princípio fundante da racionalidade instrumental, a saber, da autoconservação (sese conservare) é abandonado pela arte, pois ela não se insere de forma direta no plano das necessidades humanas, ainda que faça parte da formação dos indivíduos e se relacione com o conceito de humanidade. Contudo, sua existência não se orienta por aquela determinação racional relacionada a fins, dos quais ela se separa na medida em que aponta para um outro, para algo que não pertence ao mundo empírico, embora se vincule a ele na mediação da forma artística, ou seja, a obra de arte realiza algo como a denúncia do que não pode ser na realidade e que só consegue encontrar expressão em uma determinada forma estética. Segundo Adorno,

na relação com a realidade empírica, a arte sublima o princípio, ali actuante do sese conservare, em ideal do ser-para-si dos seus testemunhos; segundo as palavras de Schönberg, pinta-se um quadro, e não o que ele representa. Toda a obra de arte aspira por si mesma à identidade consigo, que, na realidade empírica, se impõe à força a todos os objetos, enquanto identidade com o sujeito e, deste modo, se perde. A identidade estética deve defender o não-idêntico que a compulsão à identidade oprime na realidade (ADORNO, 2008b, p. 16).

Nessa passagem, é possível observar um tema fundamental na obra de Adorno, a saber, a identidade como forma de se considerar os objetos. Diferentemente da pretensão discursiva associada à razão, Adorno atribui às formas estéticas a possibilidade de se referir ao caráter não-idêntico das coisas que a racionalidade instrumental é incapaz de apreender. Assim, a obra de arte torna-se capaz de uma relação não-violenta com os objetos, mais precisamente, por meio da combinação de elementos racionais e miméticos, sendo capaz de exprimir um conteúdo [Gehalt] objetivo não-apreensível discursivamente. Nesse sentido, a arte difere em sua expressão de uma lógica identitária calcada sobre um princípio de dominação e traz consigo a possibilidade de expressar o não-idêntico. Isso não significa, porém, que não haja contradições nas obras de arte. A contradição pode ser entendida, segundo a Dialética negativa, como "o indício da não-verdade da identidade, da dissolução de resíduos daquilo que é concebido no conceito" (ADORNO, 2009, p. 12), ou como "o não-idêntico sob o aspecto da identidade" (ADORNO, 2009, p. 13), ou ainda como a "não-identidade sob o encanto da lei que também afeta o não-idêntico" (ADORNO, 2009, p. 13). Na mesma obra, Adorno afirma que 
essa lei, contudo, "não é uma lei do pensamento. Ao contrário, ela é uma lei real" (ADORNO, 2009, p. 13). O pensamento, portanto, ao promover a identidade entre o objeto e uma formalização racional, deixa escapar de si o não-idêntico, considerando-o uma contradição. Porém, esta se reflete na ordem racional, embora exista antes dela, como realidade não absorvida pela lógica identitária. Na arte, essa relação se manifestará de maneira diversa. Considerando que para Adorno a forma estética é conteúdo sedimentado (Cf. ADORNO, 2008b, p. 17), a contradição "real" se mostrará na estrutura da própria obra de arte. É por isso que Adorno irá afirmar que

os estratos fundamentais da experiência, que motivam a arte, aparentamse com o mundo objectivo, perante o qual retrocedem. Os antagonismos não resolvidos da realidade retornam às obras de arte como os problemas imanentes da sua forma. É isto, e não a trama dos momentos objetivos, que define a relação da arte com a sociedade. As relações de tensão nas obras de arte cristalizam-se unicamente nestas e através de sua emancipação a respeito da fachada fáctica do exterior atingem a essência real (ADORNO, 2008b, p. 18).

É na forma da obra de arte, portanto, que estará presente, e de maneira mediada, um conteúdo objetivo histórico. Nesse sentido, Adorno se contrapõe às concepções subjetivistas em relação à arte. Recusa, por exemplo, a posição de Freud, para quem a arte pode ser compreendida como projeção de um inconsciente do artista, como se o momento de expressão da obra se vinculasse apenas à subjetividade e, indiretamente, à realidade que a constitui. Da mesma forma, contrapõe-se a Kant, que concebe a arte também em sua conexão com o sujeito, o qual tem uma satisfação na contemplação da obra por ela ser a representação de um objeto da faculdade de desejar. Assim, diz Adorno, "para ambos, a obra de arte encontra-se apenas em relação com aquele que a contempla ou que a produz" (ADORNO, 2008b, p. 26). Dessa forma, Adorno defenderá, contra tais autores, uma concepção que permite à obra de arte ser concebida como portadora de um conteúdo que, por sua vez, se remete não ao artista que a cria, mas a uma objetividade social.

O artista aparece, então, apenas como mediador que transporta para a obra de arte uma verdade da qual ele próprio é expressão, mas que não é projetada por ele intencionalmente e nem inconscientemente. A obra seria, assim, revestida de uma autonomia mesmo em relação ao seu criador, o qual, para ser fiel à liberdade da obra, não se aliena nela e nem a torna produto de uma suposta sublimação de suas pulsões. Essa ideia aparece também na obra Minima Moralia, na afirmação de Adorno de que: 
o sentimento da arte, seu pathos consiste em que, justamente ao recolherse na imaginação, ela faz justiça à supremacia da realidade sem contudo resignar-se à adaptação, ao não dar seqüência à violência do exterior na deformação do interior. Aqueles que realizam isso pagam, sem exceção, um preço alto como indivíduos, deixados para trás da própria expressão, que escapou à sua psicologia. [...] Nenhuma obra de arte pode esquivar-se, na organização social, da sua inclusão na cultura; mas nenhuma que seja mais do que artesanato existe sem dirigir à cultura o gesto de repúdio: o de que se tornou obra de arte. A arte é tão hostil à arte quanto aos artistas. Na renúncia ao alvo pulsional ela lhe mantém fidelidade, desmascarando nisso o socialmente desejado que Freud ingenuamente celebra como sublimação, coisa que provavelmente nem existe (ADORNO, 2008a, p. 210).

Assim, a obra de arte deve ser concebida em sua uma autonomia frente ao sujeito que a produziu, além de se desvincular de modo imediato da realidade na qual está inserida, embora a ela relacionada por meio de sua forma estética. Nesse sentido, pode-se dizer que Adorno não assume o conceito de gênio relativo à produção da obra, algo que é contraditório à própria ideia de autonomia da arte, uma vez que, segundo Bürger, uma das características das obras de arte autônomas é a individualidade que a produz e que é representante do indivíduo como particular (Cf. BÜRGER, 2008, p. 109).

A aparente incompatibilidade entre os conceitos defendidos por Adorno se dissolve no momento em que se entende que a autonomia da arte envolve a concepção do autor como sujeito que imprime na obra a objetividade social. Hohendahl compartilha essa posição ao afirmar que, para Adorno, "o autor individual entra na esfera da crítica somente como voz humana, a subjetividade histórica que objetiva a expressão através da obra. Assim, a ênfase é colocada no lado objetivo: à obra de arte autêntica é conferido o estatuto de um testamento permanente da história" (HOHENDAHL, 1981, p. 138, tradução nossa). Embora Hohendahl compartilhe essa posição, ele acaba por conceder validade às criticas de Bürger a Adorno, mesmo considerando-as enredadas no modelo estético adorniano (Cf. HOHENDAHL, 1981, p. 146).

$\mathrm{Na}$ medida em que se concebe a autonomia da arte na obra de Adorno em seu duplo caráter, muitas das críticas a ele endereçadas podem ser respondidas. Assim, é possível defender que a obra de arte autêntica teria a capacidade de exprimir algo que é, ao mesmo tempo, parte da realidade, mas que protesta contra ela. Ela se apresenta como um fato social, mas se distancia da realidade negando-a. De acordo com Bernstein, haveria um momento negativo e outro positivo da autonomia da arte (Cf. BERNSTEIN, 2004, p. 146). O primeiro está relacionado, como 
já foi mencionado anteriormente, a sua falta de finalidade na sociedade, à ausência de uma função social. Já o caráter positivo reside no fato da arte ser orientada por normas internas a sua própria atividade, por leis intrínsecas a seu desenvolvimento. Segundo o autor, "a premissa fundamental da teoria estética adorniana é a de que a autonomia da arte é tanto uma característica de obras e práticas e, ao mesmo tempo, um fato social" (BERNSTEIN, 2004, p. 146, tradução nossa). Esse duplo caráter, assim, confere à arte uma dimensão social, mas também a nega na medida em que seu desenvolvimento independe dela. Como afirma Adorno a esse respeito, "a arte é a antítese social da sociedade, e não deve imediatamente deduzir-se desta" (ADORNO, 2008b, p. 21).

A obra de arte possui uma estrutura que é produto de seu desenvolvimento interno, mas também é mediadora dos conteúdos da realidade. Sua dupla autonomia remete, consequentemente, a sua falta de finalidade e à impossibilidade de que ela seja orientada externamente: ela não visa a nenhum objetivo social e nem é determinada por ele. É dessa forma, portanto, que o caráter social da arte se relaciona com sua própria autonomia, pois aquele é garantido somente na medida em que ela não atende a nenhum interesse externo, desenvolvendo-se somente a partir de si mesma.

Nesse sentido, Adorno se opõe à identificação da arte com uma forma de hedonismo, como se a obra pudesse ser entendida a partir do sentimento de prazer que causa naquele que a contempla. De acordo com ele, "a experiência artística só é autônoma quando se desembaraça do gosto da fruição" (ADORNO, 2008b, p. 28). A recusa de Adorno em conceder à arte a finalidade de proporcionar um prazer estético se deve ao fato de que, dessa forma, a obra se sujeitaria a um objetivo prático, ao qual sua própria existência se opõe, uma vez que ela surge como autônoma diante de qualquer interesse externo. Assim, em primeiro lugar, o argumento se dirige contra a imposição à obra de arte de uma finalidade. Em segundo lugar, mas em relação com o aspecto anterior, Adorno procura mostrar que a experiência artística autêntica não está relacionada à fruição estética, mas à possibilidade de se compreender o elemento de verdade presente na obra, o qual se remete ao conteúdo [Gehalt] objetivo que ela é capaz de expressar. Como também defende Gómez, "as obras de arte não são para Adorno nenhum meio de deleite de nível superior. 'Deleite artístico' é uma categoria que a teoria descobre em sua mediação histórica" (GÓMEZ, 1994, p. 57, tradução nossa). Ainda segundo o autor, a ideia de deleite, assim como a arte, também seria um produto do desenvolvimento histórico, já que, após a declarada inutilidade da arte para a autoconservação, ela teve que se manter relevante por meio de seu valor de uso. 
Assim, a defesa de Adorno de que o prazer não é constitutivo da arte mostra-se amparada por essa consideração histórica, a qual levada adiante, conecta-se com a própria crítica à indústria cultural, contra a qual a arte genuína diverge substancialmente em relação ao sentimento ligado a sua recepção, muito mais marcado pela tensão do que pelo prazer, uma vez que ela se apresenta como um momento de negação e denúncia da realidade e de seus antagonismos. O argumento em favor do hedonismo é, segundo Adorno, equivocado:

o conceito de deleite artístico foi um compromisso infeliz entre a essência social da obra de arte e a sua natureza antitética a respeito da sociedade. Se a arte é já inútil para o sistema de autoconservação - o que a sociedade burguesa nunca lhe perdoou -, deve pelo menos preservar-se através de um tipo de valor de uso, decalcado sobre o prazer sensual. Falsifica-se assim também como ela um cumprimento físico, que os seus representantes estéticos não dispensam. Hipostasia-se o facto de que aquele que é incapaz de diferenciação sensual não consegue distinguir um belo acorde de um acorde sem brilho, cores cintilantes de cores embaciadas, é dificilmente apto para a experiência artística. Esta experiência recebe, no entanto, intensificada, a diferenciação sensual como meio de estruturação em si, mas não difunde o prazer senão de um modo fragmentário (ADORNO, 2008b, p. 31).

Contudo, há um momento de verdade no hedonismo, pois há um prazer não intencional que, eventualmente, pode ser provocado pela obra de arte. Ele é, porém, inessencial a ela, não sendo constitutivo de seu caráter estético. A crítica de Adorno ao prazer subjetivo como constitutivo da obra de arte também se refere ao momento histórico do qual sua reflexão emerge: em uma época em que a consciência, assim como a arte, sofre um processo de reificação, é impossível conceber que o prazer advindo da experiência artística seja considerado genuíno, pois ele aparece como fuga de uma realidade mais do que como momento suscitado pela obra de arte. Como afirma Adorno,

quem saboreia concretamente as obras de arte é um filistino; expressões como 'festim para ouvido' bastam para o convencer. Mas, se se extirpasse todo o vestígio de prazer, levantar-se-ia a questão embaraçosa de saber porque é que as obras de arte ali estão. $\mathrm{Na}$ verdade, quanto mais se compreendem as obras de arte, tanto menos se saboreiam (ADORNO, 2008b, p. 29).

Desse modo, fica explícita a independência do sentimento causado pela obra de arte para sua definição. Aqui se pode relembrar a crítica de Adorno às abordagens estéticas de Kant ou mesmo de Freud, as quais conservam em sua concepção de arte a relação entre a obra e o 
sujeito ou, como diz Gómez (1994, p. 63, tradução nossa), "tanto para Kant como para Freud a obra de arte está unicamente em relação ou com quem a observa ou com quem a produziu". A crítica de Adorno se realizará de forma imanente, observando a estrutura da obra e o modo como ela é expressão de um determinado momento histórico e objetivo da sociedade. Nesse sentido, Adorno se distancia da estética hegeliana que, embora tenha defendido a autonomia da obra em razão dela expressar um teor de verdade, posição essa que Adorno também assume, concebeu o conceito de belo como identidade entre espírito e verdade. A forma com que Adorno realizará sua crítica, ao contrário, procura resgatar o não-idêntico como conteúdo objetivo que rompe com o modelo idealista da estética hegeliana. É assim que Adorno sustentará a ideia de que "o momento estético da forma encontra-se assim ligado à ausência de violência" (ADORNO, 2008b, p. 21), pois a obra de arte absorve a contraditoriedade da realidade em sua estrutura, embora não a dissolva.

\section{Referências}

ADORNO, Theodor W. Dialética negativa. Tradução de Marco Antonio Casanova. Rio de Janeiro: Zahar, 2009.

. Minima Moralia: reflexões a partir da vida lesada. Tradução de Gabriel Cohn. Rio de Janeiro: Azougue, 2008a.

ADORNO, Theodor W. "Teoria da semiformação". Tradução de Newton Ramos-deOliveira. In: PUCCI, Bruno; ZUIN, Antônio Alvaro Soares; LASTÓRIA, Luiz Antonio Calmon Nabuco (Org.). Teoria crítica e inconformismo: novas perspectivas de pesquisa. Campinas: Autores Associados, 2010, p. 7-40.

. Teoria estética. Tradução de Artur Morão. Lisboa: Edições 70, 2008b.

"O fetichismo na música e a regressão na audição". In: Os Pensadores. São Paulo: Abril Cultural, 1975.

. "Zur gesellschaftlichen Lage der Musik" [Sobre a situação social da música]. In: ADORNO, Theodor W. Gesammelte Schriften. Frankfurt am Main/Berlin: Suhrkamp/ Directmedia, 2003. (Digitale Bibliothek Band 97). CD-ROM.

ALMEIDA, Jorge de. Crítica dialética em Theodor Adorno. Música e verdade nos anos vinte. Cotia: Ateliê Editorial, 2007.

BENJAMIN, Walter. "A obra de arte na era de sua reprodutibilidade técnica". Tradução de Sérgio Paulo Rouanet. In: Obras escolhidas I. São Paulo: Brasiliense, 1994a.

BERNSTEIN, J. M. "Adorno's Aesthetic Theory". In: RUSH, Fred (Ed.). The Cambridge Companion to Critical Theory. Cambridge: Cambridge University Press, 2004.

BÜRGER, Peter. Teoria da vanguarda. São Paulo: Cosac Naify, 2008.

GÓMEZ, Vicent. "Estética y Teoría de La Racionalidad. Un studio sobre "Teoría Estética'”. In: WELLMER, Albrecht; GÓMEZ, Vicent. Teoría crítica y estética: dos interpretaciones de Th. Adorno. Valencia: Guada, 1994. 
HARDING, James M. Historical dialectics and the autonomy of art in Adorno's asthetische theorie. The Journal of Aesthetics and Art. Criticism 50:3, Summer, 1992.

HOHENDAHL, Peter Uwe. "Looking Back at Adorno's Äesthetische Theorie". The German Quarterly, 54, 2 (Mar. 1981), p. 133-148.

PADDISON, Max. Adorno's Aesthetics of music. Cambridge, New York: Cambridge University Press, 1993.

PETRY, Franciele Bete. Além de uma crítica à razão instrumental. 2011. 252 f. Tese (Doutorado) - Curso de Programa de Pós-graduação em Filosofia, Universidade Federal de Santa Catarina, Florianópolis, 2012. Disponível em: < http://www.tede.ufsc.br/ teses/PFIL0149-T.pdf>. Acesso em: 31 jan. 2015.

SAFATLE, Vladimir. "O novo tonalismo e o esgotamento da forma crítica como valor estético". In: DUARTE, Rodrigo; SAFATLE, Vladimir (Org.). Ensaios sobre música e filosofia. São Paulo: Associação Editorial Humanitas, 2007.

\section{Endereço postal:}

Universidade Federal de Santa Catarina - UFSC

Departamento de Estudos Especializados em Educação

Centro de Ciências da Educação

Campus Professor João David Ferreira Lima - Trindade

88040-900 Florianópolis, SC, Brasil

Data de recebimento: 30/01/2014

Data de aceite: 23/05/2014 